\title{
Caracterização morfológica, mineralógica e química dos níveis de alteração da Formação Marília (Membro Serra da Galga) do Neocretáceo da Bacia Bau- ru, no Triângulo Mineiro (MG)
}

\author{
Carla Vanessa de Sousa COELHO ${ }^{1}$ \& Vania ROSOLEN ${ }^{2}$
}

(1) Programa de Pós-Graduação em Geologia e Meio Ambiente, Instituto de Geociências, Universidade Estadual Paulista "Júlio de Mesquita Filho". Caixa Postal 178, CEP 13506-900, Rio Claro, SP, Brasil. E-mail: carla.vsc1@gmail.com.

(2) Departamento de Petrologia e Metalogenia, Instituto de Geociências, Universidade Estadual Paulista "Júlio de Mesquita Filho". Caixa Postal 178, CEP 13506-900, Rio Claro, SP, Brasil. E-mail: vrosolen@rc.unesp.br.

Recebido em 11/2014. Aceito para publicação em 04/2016.

Versão online publicada em 31/05/2016 (www.pesquisasemgeociencias.ufrgs.br)

\begin{abstract}
Resumo - Nos planaltos tabulares do Triângulo Mineiro, os sedimentos da Formação Marília (Neocretáceo) são intensamente alterados e pedogeneizados formando perfis espessos, muito argilosos com elevada concentração de caulinita e gibbsita. 0 objetivo deste trabalho é caracterizar as principais alterações petrográficas (microscopia ótica), mineralógicas (DRX e ATD-TG) e geoquímicas (FRX e Função de Transporte Geoquímico) em um perfil de alteração envolvendo o arenito, o saprolito e os horizontes superficiais plínticos e com argilas aluminosas. Os resultados mostraram que a caulinita e a gibbsita são a paragênese secundária dominante no perfil. As concentrações se acentuam na alterita, devido à alteração de feldspatos e minerais micáceos e, mais acentuadamente na plintita e na argila aluminosa. Nos horizontes superficiais, a concentração de gibbsita é maior que a da caulinita. A geoquímica e a função de transporte mostraram aumento dos óxidos de ferro na alterita $(1,45 \%)$ e na plintita $(2,66 \%)$ devido à concentração absoluta nos nódulos. Na alterita ocorrem ganhos absolutos de $\mathrm{Si}, \mathrm{Al}$ e Fe. Houve perda de Si na plintita e na argila aluminosa. Em relação ao Al, observa-se ganhos na alterita, plintita e na argila aluminosa. A proporção de gibbsita em relação à caulinita aumenta da base para o topo do perfil, passando de $\sim 72 \%$ de caulinita $\mathrm{e}$ $\sim 3 \%$ de gibbsita no arenito para $\sim 28 \%$ de caulinita e $\sim 71 \%$ de gibbsita na argila aluminosa, indicando meio fortemente dessilicificado. Os resultados obtidos mostram estreita similaridade entre os materiais analisados, sugerindo possível filiação mineralógica.
\end{abstract}

Palavras-chave: Arenito, plintita, argila aluminosa.

\begin{abstract}
MORPHOLOGICAL, MINERALOGICAL AND CHEMICAL CHARACTERIZATION OF THE ALTERATION levels of Marília Formation (Serra da Galga Member) from the Neo Cretaceous of Bauru BASIN, IN THE TRIÂNGULO MinEIRo (MG) In the flat plateaus of the Triângulo Mineiro, the sediments of Marília Formation (Neo Cretaceous) are intensively altered and pedogenised, developing thick profiles, strongly clayey with high concentrations of kaolinite and gibbsite. The objective of this paper is to characterize the major changes of petrography (optical microscopy), mineralogical (XRD and DTA-TG) and geochemical (XRF Geochemical Transport and function) in an alteration profile involving the sandstone, the saprolite and the superficial plinthic horizons and with aluminous clays. The results have shown that the kaolinite and gibbsite are the dominant secondary paragenesis of the profile. The concentrations are accentuated in the saprolite on account of the weathering of feldspars and micaceous minerals, and it is most present in the plinthite and in the aluminous clay. In the superficial horizons, the gibbsite concentration is higher than the kaolinite. The geochemical data and the transport function have shown that there is an increase of iron oxides in saprolite $(1.45 \%)$ and in the plinthite $(2.66 \%)$ due to the absolute concentration in the nodules. In saprolite there are absolute gains of $\mathrm{Si}, \mathrm{Al}$ and $\mathrm{Fe}$. There was loss of $\mathrm{Si}$ in the plinthite and in the aluminous clay. Regarding the $\mathrm{Al}$, it is noticed gains in the saprolite, plinthite and aluminous clay. There is a relative increase in the proportion of kaolinite and gibbsite from the base to the top of the profile, from $\sim 72 \%$ of kaolinite and $\sim 3 \%$ of gibbsite in the sandstone and from to $\sim 28 \%$ of kaolinite and $\sim 71 \%$ of gibbsite in aluminous clay, indicating strong loss of silica in the soil solution. The results obtained show strong similarity between the analyzed samples, suggesting a possible mineralogical relationship among them.
\end{abstract}

Keywords: Sandstone, plinthite, aluminous clay. 


\section{Introdução}

As coberturas lateríticas são comuns nas estruturas cratônicas e tectonicamente estáveis das regiões intertropicais, e exibem grande complexidade química e mineralógica herdada de vários ciclos evolutivos (Nahon et al., 1989; Brimhall et al., 1991). Espessos mantos de intemperismo se formam sobre todas as litologias e desenvolvem uma matriz secundária argilosa que, de acordo com suas características morfológicas, mineralógicas e geoquímicas, são profundamente diferentes daquelas que caracterizam o material original (Butt et al., 2000).

Um perfil de solo laterítico possui uma sucessão de horizontes organizados verticalmente que exibem estruturas e texturas contrastantes. Geralmente apresenta, da base para o topo, a alterita, que resulta da alteração isovolumétrica do material parental, o horizonte plíntico endurecido contínuo (crosta) ou descontínuo (nodular), com enriquecimento absoluto de ferro e, no topo, os horizontes argilosos relativamente homogêneos, friáveis e bioturbados (Tardy, 1993).

Os sistemas pedológicos organizados nas coberturas lateríticas exibem acumulação preferencial de caulinita, acumulação e endurecimento de estruturas com óxidohidróxidos de ferro (hematita e goethita) ou ainda de produtos aluminosos (gibbsita) e bauxitas, além de $\mathrm{Mn}, \mathrm{Ni}$, Co e Au entre outros, todos com relevante significado metalogenético e industrial (Melfi et al., 1979; Birmhall et al., 1991; Montes et al., 2002; Costa et al., 2009).

As concentrações químicas e mineralógicas ainda são insuficientemente caracterizadas e entendidas, em parte porque a rocha sã encontra-se em grandes profundidades e o longo e intenso intemperismo modificam as fácies de alteração. 0 avanço das pesquisas relacionadas com as coberturas lateríticas é essencial para entender a história geológica das paisagens tropicais e para a exploração mineral.

O Brasil comporta uma das maiores concentrações de caulim e bauxita do mundo, cuja gênese está majoritariamente relacionada com os perfis lateríticos maduros (Costa et al., 2009). No estado de Minas Gerais, os planaltos tabulares (chapadas) do Triângulo Mineiro possuem elevada concentração de argila aluminosa (caulinita e gibbsita), algumas em fase de exploração, que em estudos anteriores foram considerados como enriquecimento em material alóctone (Corrêa, 1989, 2006) ou material produzido por alteração in situ (Suguio et al., 1976; Lara, 1997). São economicamente importantes e foram requeridas para a extração de argilas refratárias $\left(107,53 \mathrm{~km}^{2}\right)$ ou argilas $(301,13$ $\mathrm{km}^{2}$ ) (Borges, 2012).

O objetivo deste artigo é caracterizar, a partir de perfis com afloramento da alteração do arenito e da lavra a céu aberto, as propriedades morfológicas, químicas e mineralógicas da alteração laterítica do arenito da Formação Marília (Membro Serra da Galga), pertencente à Bacia Bauru, com base em informações petrográficas, mineralógicas e geoquímicas. 0 termo "Bacia Bauru" consiste em uma denominação proposta por Fernandes \& Coimbra (1996) para a entidade geotectônica neocretácea constituída pelos grupos Caiuá e Bauru.

\section{2 Área, materiais e métodos}

\section{1 Área de estudo}

A área de estudo está situada entre os municípios de Uberaba e Uberlândia $\left(19^{\circ} 20^{\prime} 20^{\prime \prime}\right.$ Sul e $53^{\circ} 56^{\prime} 14^{\prime \prime}$ Oeste) no Triângulo Mineiro (Fig. 1).

No Triângulo Mineiro, os planaltos tabulares (chapadas) são formas de relevos esculpidas nas unidades sedimentares supra-basálticas cretáceas pertencentes ao Grupo Bauru.

Os sedimentos do Grupo Bauru foram depositados em uma bacia homônima, formada por compensação isostática posterior ao acúmulo de quase $2.000 \mathrm{~m}$ de lavas basálticas, ocorrido no Cretáceo Inferior (Ricomini, 1997; Fernandes \& Coimbra, 2000; Tavares, 2012). A Bacia Bauru formou-se no Neocretáceo, no centro-sul da Plataforma Sul-Americana, e desenvolveu-se como bacia continental interior, pós-ruptura do continente gondwânico, acumulando uma sequência sedimentar essencialmente arenosa, hoje com espessura máxima de cerca de $300 \mathrm{~m}$ e área de $370.000 \mathrm{~km}^{2}$ (Fernandes \& Coimbra, 2000). A seqüência tem por substrato basaltos da Formação Serra Geral (Grupo São Bento), dos quais é separada por não-conformidade, e limite superior erosivo, demarcado pela Superfície Sul-Americana ou sua posterior dissecação (Fernandes \& Coimbra, 2000).

A seqüência suprabasáltica neocretácea é composta pelos grupos Bauru e Caiuá (Fernandes \& Coimbra, 2000). Seu contato basal é discordante (não-conformidade), sobretudo com basaltos da Formação Serra Geral (Grupo São Bento). A passagem lateral entre os grupos Caiuá e Bauru é gradual e interdigitada (Fernandes, 2004). 0 Grupo é constituído pelas formações Araçatuba, Adamantina, Uberaba e Marília (Batezelli et al. 2003).

A chapada estudada é sustentada pelos arenitos da Formação Marília, mais especificamente 


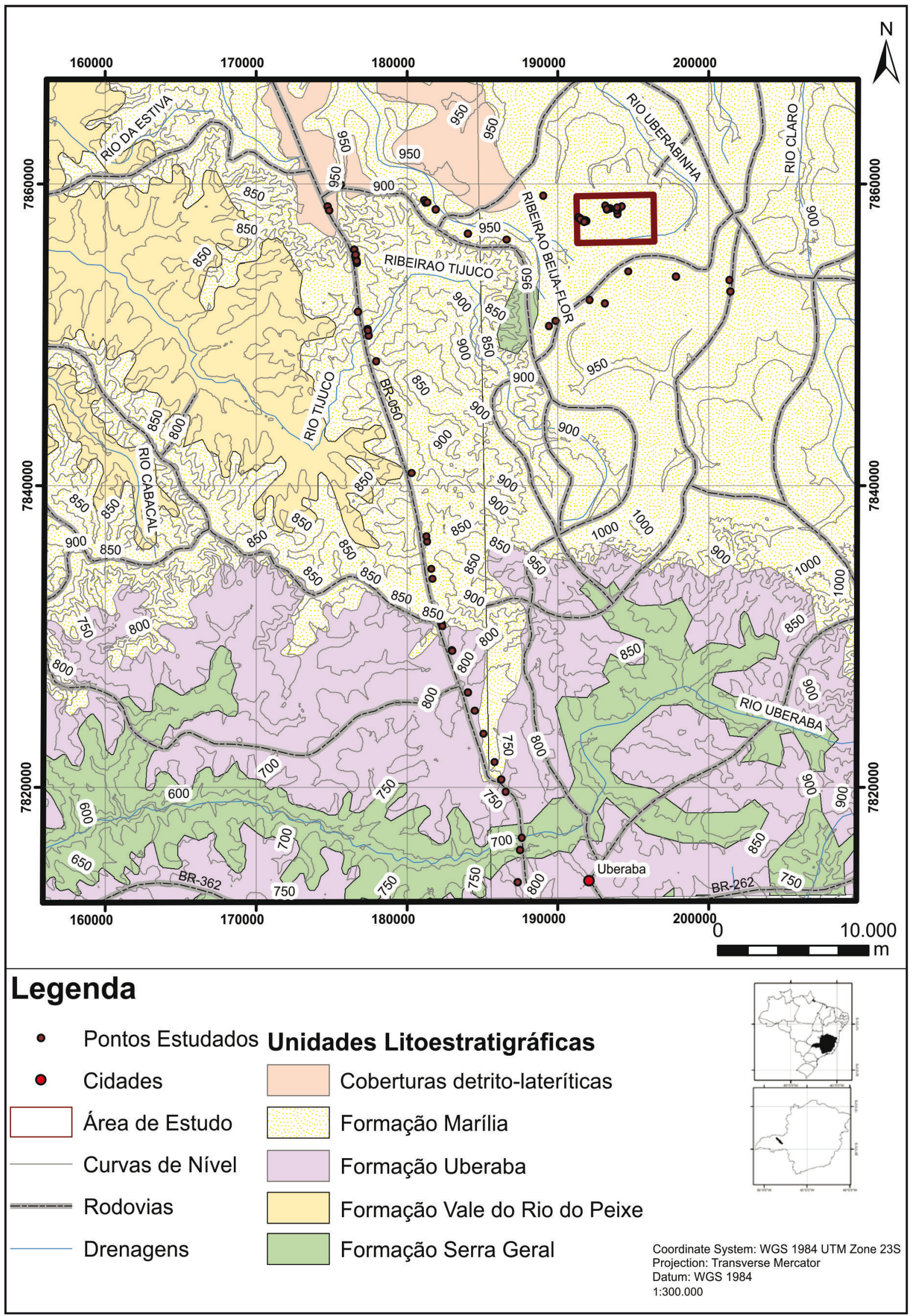

Figura 1. Mapa geológico da região da Chapada Sedimentar do Triângulo Mineiro e localização da área estudada no topo da chapada. 
pelo Membro Serra Galga, depositado entre aproximadamente 86 e 74 Ma. (Suguio, 1973) que recobre as formações mais antigas e aflora localizadamente nas bordas íngremes do planalto. 0 Membro Serra da Galga constitui-se predominantemente por subarcóseos líticos e, secundariamente, por litoarenitos, sublitoarenitos e litoarenitos feldspáticos, mal a pobremente selecionados (Ribeiro, 2001). Tais arenitos são imaturos e formados em ambiente semi-árido, com cores amarelas a avermelhadas, originadas de sedimentação fluvial de leques aluviais e lagos efêmeros (Suguio, 1973). Também podem estar parcialmente cimentados ou conter nódulos de $\mathrm{CaCO}_{3}$ e crostas de sílex de espessura centimétrica (Fernandes \& Coimbra, 2000). Cutículas e agregados argilosos são compostos por illita, esmectita e interestratificado illita-esmectita (Ribeiro, 2001).

A cobertura é composta por latossolos amarelos a amarelo-avermelhados e gleissolos. Os latossolos estão presentes nas partes melhor drenadas do platô enquanto os gleissolos estão presentes nas depressões topográficas insuficientemente drenadas, desenvolvidas na superfície do platô (Rosolen et al., 2014), locais de extração das argilas aluminosas (argilas refratárias).

O clima é tropical com temperatura média anual de $23^{\circ} \mathrm{C}$ e precipitação média de $1464 \mathrm{~mm} /$ ano, sendo dezembro e janeiro os meses mais chuvosos, representando cerca de $41 \%$ da precipitação anual média (Queiroz, 2012). Recoberta pela vegetação de Cerrado, esta região faz parte do núcleo da paisagem laterítica que está relacionada com as velhas superfícies de erosão tectonicamente estáveis do Escudo Central Brasileiro (Melfi, 1997).

\subsection{Descrição do perfil}

Em decorrência da grande espessura do regolito, as amostras foram coletadas em duas situações: no afloramento do Membro Serra da Galga na borda da chapada e na cava de extração de argila. 0 perfil apresentado é composto pelo arenito, a alterita (ou saprolito), a plintita e o horizonte de argila aluminosa (Fig. 2).

0 arenito estratificado é vermelho (10R 6/4) com zonas amarelo avermelhadas (7,5YR 7/6) e volumes de argila branca, pouco compacto, composto por grãos sub-arredondados de quartzo fino a médio. A alterita é mosqueada combinando cores amarelo pálida (2,5YR 7/6) e vermelho pálido (7,5YR 7/4). Corresponde a um material muito friável que se individualiza em grãos de quartzo (areia) e partículas de argila e silte predominante- mente vermelhas.

Os horizontes pedogenéticos que se sobrepõem ao arenito e a alterita são da base para o topo: (i) 120-170+ cm: horizonte argiloso plíntico composto por volumes vermelhos escuros endurecidos (10R 2,5/2), volumes friáveis vermelho (2,5YR 4/8), vermelho amarelado (5YR 5/6) a amarelo avermelhado (5YR 6/8) e menor proporção de volumes cinza claro (10YR 7/1), argiloso com pisólitos (mm-cm). Abaixo desta profundidade, o solo foi tradado e a plintita se transforma em um material homogêneo vermelho (2,5 YR 5/8) e encontra-se submersa no lençol; (ii) 70-120 cm: horizonte com argila aluminosa, coeso, microgranular $(<0,3 \mathrm{~mm})$, cinza claro $(2,5 \mathrm{Y} 7 / 2)$ com raros volumes $(\mathrm{cm})$ amarelos (2,5 Y 7/8) e vermelhos claros (7,5YR 7/3); (iii) 0-70 cm: horizonte superficial preto composto por material orgânico parcialmente preservado em meio hidromórfico.

\subsection{Análise petrográfica}

As amostras indeformadas do arenito, da alterita, plintita e argila aluminosa foram impregnadas com resina araldite e confeccionadas seções delgadas de $3 \times 5 \mathrm{~cm}$. A descrição foi feita em microscópio petrográfico Olympus BX40 binocular com luz transmitida e as fotos foram obtidas em microscópio petrográfico Zeiss Axioskop 40, com câmera fotográfica Canon de 5.0 megapixels e zoom de 4.0, do vezes Departamento de Petrologia e Metalogenia - Universidade Estadual Paulista "Júlio de Mesquita Filho" (DPM/UNESP).

2.4 Análises químicas, mineralógicas, função de transporte geoquímico (FT) e grau de intemperismo.

A análise química total foi feita em Espectrômetro de Fluorescência de Raios X (DPM/UNESP). Foram quantificados os óxidos totais de silício $\left(\mathrm{SiO}_{2}\right)$, titânio $\left(\mathrm{TiO}_{2}\right)$, alumínio $\left(\mathrm{Al}_{2} 2 \mathrm{O}_{3}\right)$, ferro $\left(\mathrm{Fe}_{2} \mathrm{O}_{3}\right)$, manganês $(\mathrm{MnO})$, magnésio ( $\left.\mathrm{MgO}\right)$, cálcio $(\mathrm{CaO})$, sódio $\left(\mathrm{Na}_{2} \mathrm{O}\right)$, potássio $\left(\mathrm{K}_{2} \mathrm{O}\right)$ e fósforo $\left(\mathrm{P}_{2} \mathrm{O}_{5}\right)$.

A função de transporte para estimar ganhos e perdas de elementos químicos no perfil em relação à rocha foi feita segundo o método de Chadwick et al. (1990). A lixiviação e o enriquecimento de um elemento ocorrem quando FT é inferior $(<0)$ ou superior $(>0)$ ao determinado na rocha $(0)$, respectivamente. 0 cálculo da FT considerou o titânio na forma de TiO como estável no processo de intemperismo (Chadwick et al., 1990). A mobilidade do Ti (assim como do Th e Zr) é baixa nos perfis 


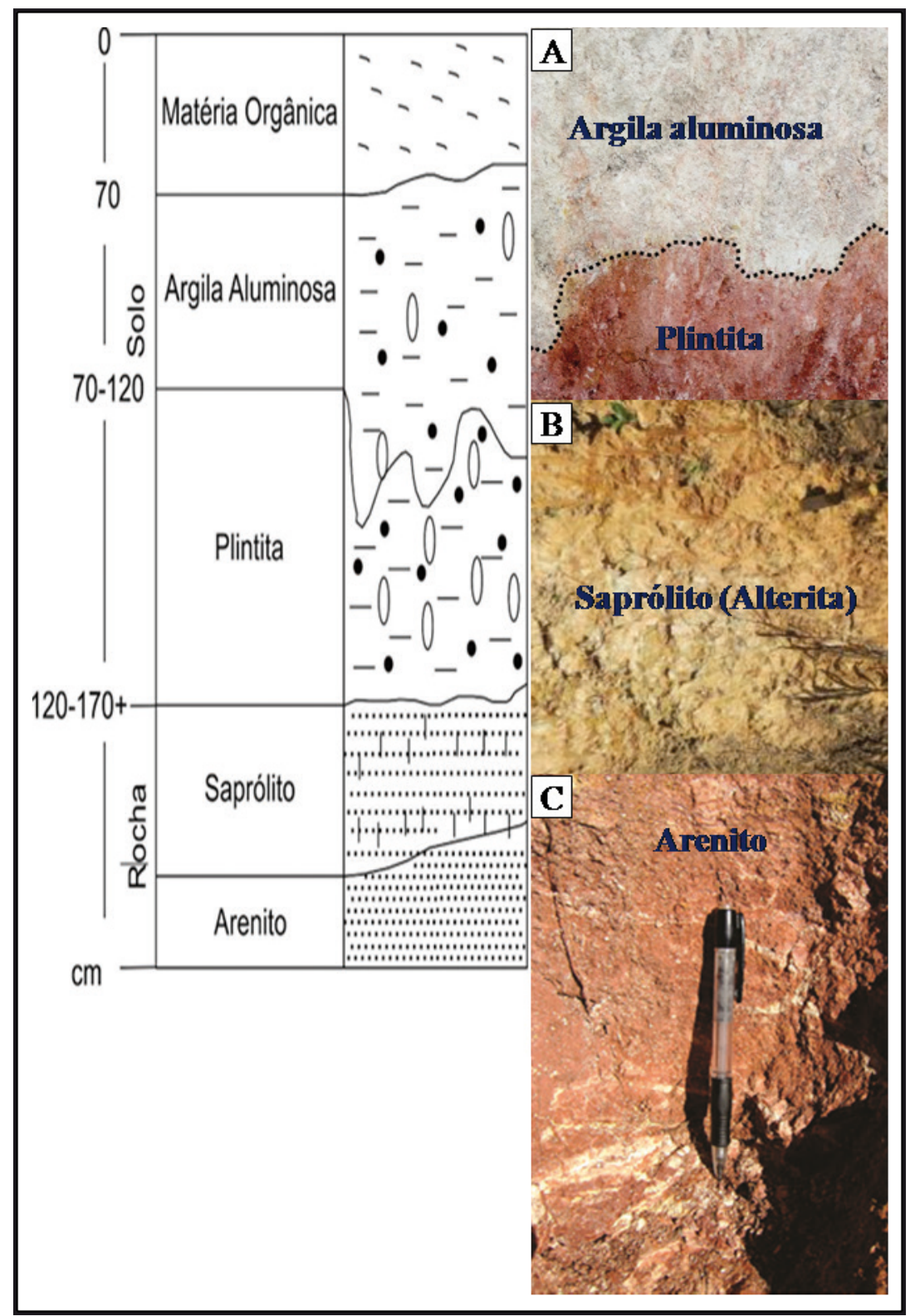

Figura 2. Perfil esquemático representando a sequência pedológica. A) Argila Aluminosa, cor cinza claro, e Plintita, cor vermelha; B) Saprólito - cor amarela; C) Arenito, cor vermelha com manchas brancas.

lateríticos por estar incorporado nos minerais secundários estáveis ou em pequenas partículas de minerais primários, principalmente no anatásio (Fritsch et al., 2005).

O grau de intemperismo foi indicado pelos índices propostos por Chen et al. (2014): $\mathrm{Al}_{2} \mathrm{O}_{3} / \mathrm{SiO}_{2}$ (fator alumina-sílica), $\left(\mathrm{Al}_{2} \mathrm{O}_{3}+\mathrm{Fe}_{2} \mathrm{O}_{3}\right) / \mathrm{SiO}_{2}$ (fator residual), $\left(\mathrm{K}_{2} \mathrm{O}+\mathrm{Na}_{2} \mathrm{O}\right) / \mathrm{Al}_{2} \mathrm{O}_{3}$ (fator de lixiviação de metais alcalinos) e $\left(\mathrm{K}_{2} \mathrm{O}+\mathrm{Na}_{2} \mathrm{O}+\mathrm{CaO}+\mathrm{MgO}\right) /$ $\mathrm{Al}_{2} \mathrm{O}_{3}$ (fator de lixiviação do total de bases).

A composição mineralógica da amostra total e da fração argila foi obtida por difratometria de raios $X$ (DRX). Foi utilizado um difratômetro Phillips PW 1730 operado com potencial de $40 \mathrm{kV}$, com uso de monocromador para a eliminação da radiação $\mathrm{K} \beta$ e fonte de $\mathrm{Cu}$ (radiação $\mathrm{K} \alpha, \lambda=1,54186$ $\AA ̊$ ). A varredura foi realizada com passo de $0,02^{\circ}$ (20) e tempo de acumulação de $10 \mathrm{~s}$ por passo.
A análise Térmica Diferencial (ATD) e Termogravimétrica (TG) permite a identificação e semiquantificação da caulinita e da gibbsita. Foram realizadas as análises da fração argila em um analisador Shimadzu DTG-60H-Simultaneous DTA-TG. A alumina calcinada e termicamente inerte foi usada como padrão de referência. Os picos endotérmicos da gibbsita e da caulinita estão em torno de 260 e $500^{\circ} \mathrm{C}$, respectivamente (Fabris et al., 2009). A caulinita quando submetida a ciclo de aquecimento sofre transformações térmicas que se iniciam com sua desidroxilação e terminam com a formação da mulita. Salienta-se que os valores da temperatura de nucleação da mulita ocorrem entre 970 e $980^{\circ}$ C e estão relacionados ao ordenamento estrutural da caulinita, ou seja, em caulinitas com baixo grau de ordem estrutural este valor ocorre por volta de 975으 (Ishida, 2010). 


\section{Resultados}

\subsection{Caracterização petrográfica}

0 arenito é formado por grãos de quartzo (entre 0,01 e $3 \mathrm{~mm}$ ) associados com feldspato potássico, plagioclásio, muscovita e biotita (Fig. 3A). Os grãos são cimentados, recobertos ou envoltos por cutãns argilo-ferruginoso. Foram identificadas duas matrizes distintas: (1) uma composta por grãos de quartzo com cimento argilo-ferruginoso e (2) outra composta por grãos de quartzo com cimento argiloso amarelo claro e comparativamente menos denso. As concentrações ferruginosas (Fig. 3B) são reconhecidas pela cor vermelha escura
(LN) e estão em contato direto com o plasma amarelo claro. Na alterita foram identificados grãos de quartzo similares aos encontrados no arenito, alguns com feições corrosivas. Sob luz natural, o mesmo material ferruginoso do arenito impregna as fraturas e recobre os grãos, indicativo de remobilização ferruginosa. Também são identificados minerais micáceos alterados e orientados (massépico a bimassépico em nicóis cruzados) associados com caulinita, contendo núcleos vermelhos densos e opacos (Fig. 3C e 3D).

Na plintita, o fundo matricial é composto por quartzo, caulinita finamente cristalizada, nódulos ferruginosos vermelhos, muito escuros, isóticos, opacos, com córtex de alteração vermelho e amarelo e limitado por plasma caulinítico cinza claro

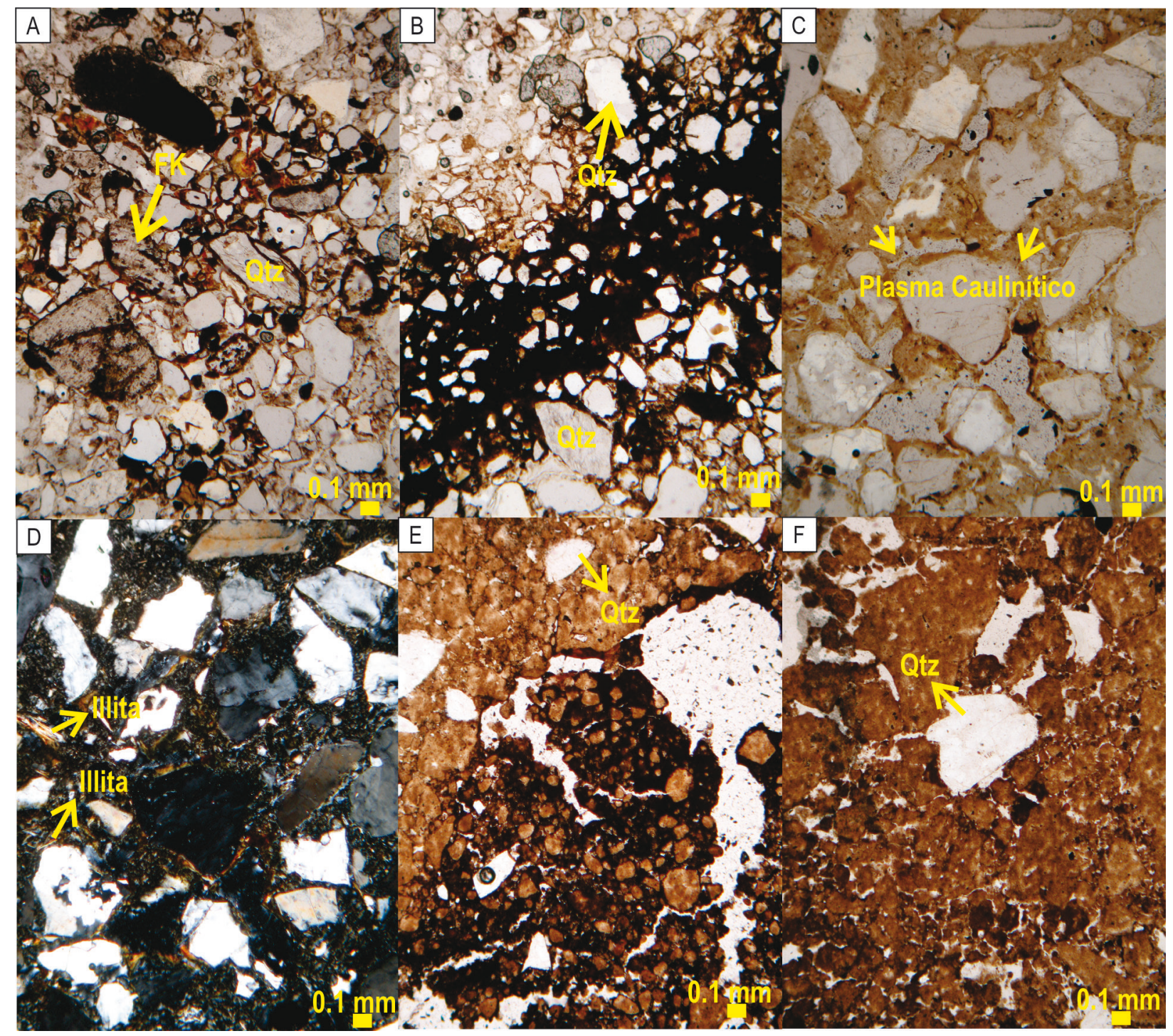

Figura 3. Fotomicrografia dos horizontes analisados: A) arenito composto por grãos de quartzo, alguns fraturados apresentando incrustações e películas argilo-ferruginosas associados com matriz fina caulinítica e grãos feldspáticos (LN); B) bandas argilosas cauliníticas claras associadas com bandas ferruginosas densas (LN); C) alterita composta por quartzo e matriz amarela clara caulinítica (LN); D) alterita com grãos de quartzo e matriz argilosa composta por caulinita e minerais micáceos birrefringentes (LP); E) plintita apresentando zonas ferruginosas hematíticas densas (nódulos) associada com matriz caulinítica clara, com desenvolvimento de forte porosidade tubular biológicas. Desenvolvimento de estrutura microgranular biológica e, possivelmente, ligada à presença da gibbsita; F) argila aluminosa ptoto e microgranular individualizando uma rede fina de poros. Destaque para a diminuição dos grãos de quartzo na plintita e argila aluminosa. 
desferruginizados e forte bioturbação (Fig. 3E). A argila aluminosa apresenta matriz composta por plasma caulinítico muito fino, o plasma é individualizado por uma rede de porosidade muito fina, com relíquias da plintita vermelha e amarela e forte bioturbação (Fig. 3F).

\subsection{Perfil mineralógico e geoquímico}

\subsubsection{Perfil mineralógico}

A composição mineralógica da amostra bruta (Fig. 4A) indica que o arenito é composto majoritariamente por quartzo (picos nas posições 3,34 e $4,25 \AA)$, caulinita $(7,14$ e $3,56 \AA$ ) $)$ goethita $(2,45$ $\AA$ A) e hematita $(1,81 \AA)$. A alterita tem composição mineralógica similar exceto pela presença do anatásio (2,38 Å). Na plintita e na argila aluminosa destaca-se a gibbsita (picos em 4,84, 4,37, 4,33 Å). Nota-se que a principal associação mineralógica no arenito e na alterita é o quartzo predominante (intensidade relativa do pico a $100 \%$ ) com caulinita enquanto que na plintita e na argila aluminosa predomina a gibbsita (intensidade relativa do pico a $100 \%$ ) com caulinita e quartzo.

Considerando apenas a fração argila (Fig. 4B), no arenito aparece pico de mineral micáceo (muscovita/illita na posição de $10 \AA ̊)$ que desaparece nos horizontes sobrejacentes, indicando alteração e formação da caulinita (picos em 7,17 e 3,57 ̊̊)

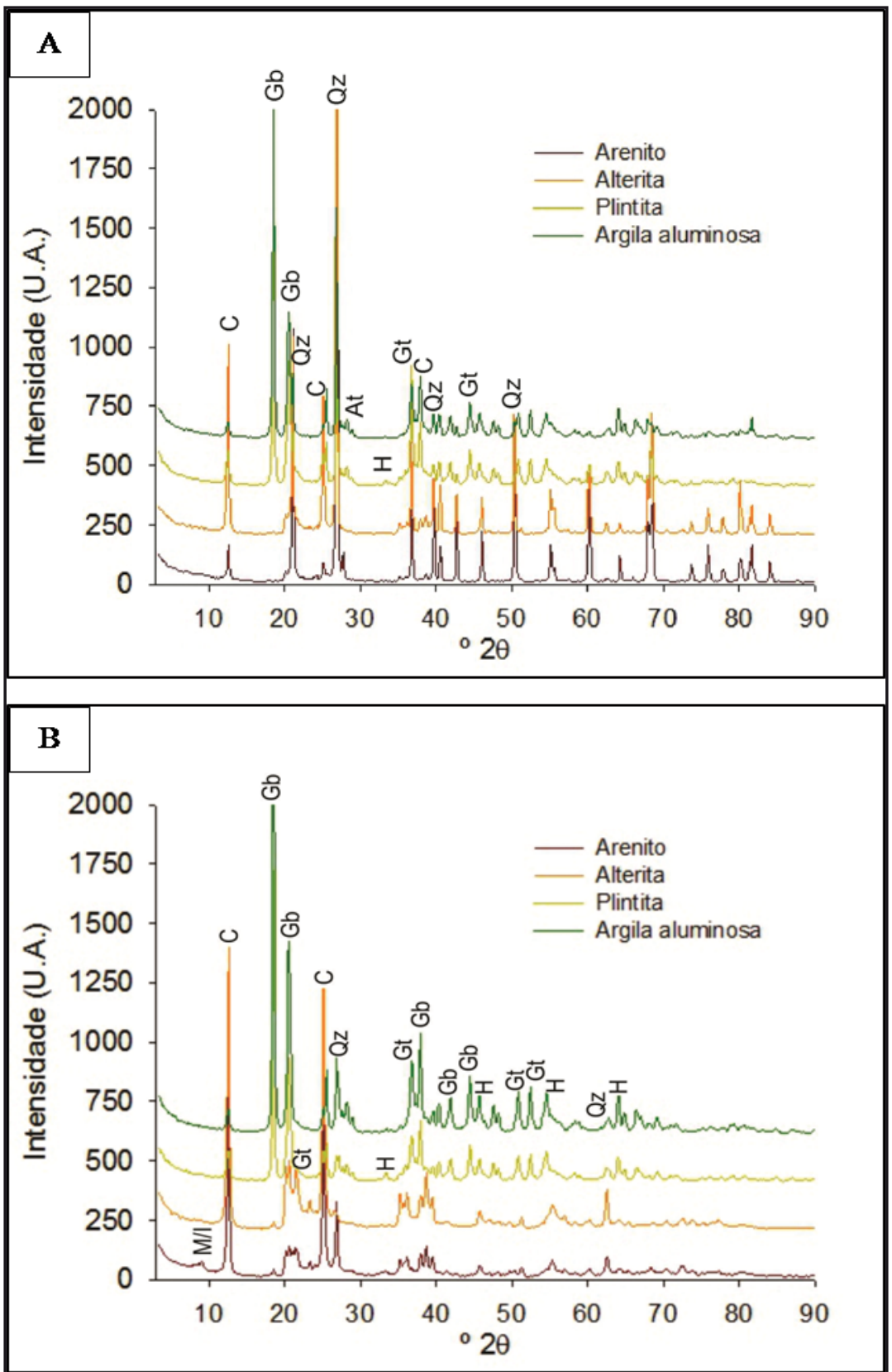

Figura 4. Difratogramas de raios X. A) Composição mineralógica da amostra bruta predominando caulinita (C), gibbsita (Gb), quartzo $(\mathrm{Qz})$, hematita $(\mathrm{H})$, goethita (Gt), anatásio (At); B) Composição mineralógica da fração argila predominando mineral micáceo $(\mathrm{M} / \mathrm{I})$, caulinita $(\mathrm{C})$, gibbsita $(\mathrm{Gb})$, Quartzo $(\mathrm{Qz})$, hematita $(\mathrm{H})$, goethita $(\mathrm{Gt})$, maghemita $(\mathrm{Mh})$. 
que passa a ser o argilomineral predominante a partir da alterita. Picos de gibbsita $(4,85,4,37$ e 2,17 Å) são identificados discretamente no arenito e tornam-se determinantes na plintita e argila aluminosa. 0 quartzo $(3,34 \AA)$ também aparece como componente mineral da fração argila em todos os horizontes indicando intenso fracionamento ou reprecipitação da sílica. Picos principais da goethita $(4,18 \AA$ ̊ ) ocorrem no arenito e na alterita indicando meios mais hidratados, enquanto picos da hematita $(2,69 \AA)$ ocorrem na plintita, coerente com a concentração ferruginosa nodular. Os óxidos de ferro predominates são a hematita e goethita e o hidróxido de alumínio, a gibbsita.
3.2.2 Óxidos totais, lixiviação e enriquecimento geoquímico no perfil e função de transporte geoquímico

No perfil, são expressivas apenas as variações dos teores dos óxidos $\mathrm{SiO}_{2}, \mathrm{TiO}_{2}, \mathrm{Al}_{2} \mathrm{O}_{3}$ e $\mathrm{Fe}_{2} \mathrm{O}_{3}$, uma vez que os cátions básicos ( $\mathrm{MnO}, \mathrm{MgO}, \mathrm{CaO}$, $\mathrm{Na}_{2} \mathrm{O}, \mathrm{K}_{2} \mathrm{O}$ ) estão ausentes do meio caracterizando ambientes de alteração laterítica (Tab. 1). A alta concentração de alumínio em base calcinada nos horizontes de plintita e argila aluminosa caracteriza a importância econômica do material, uma vez que elevados teores de $\mathrm{Al}_{2} \mathrm{O}_{3}$ tendem a aumentar a refratariedade da argila (Sampaio et al., 2005).

Tabela 1. Óxidos totais expressos em porcentagem (\%), $\mathrm{Al}_{2} \mathrm{O}_{3} \mathrm{em}$ base calcinada e Índices de Intemperismo para as amostras de Argila Aluminosa, Alterita, Plintita e Arenito.

\begin{tabular}{|c|c|c|c|c|c|c|c|c|c|c|c|c|c|}
\hline Amostra & $\mathrm{SiO}_{2}$ & $\mathrm{TiO}_{2}$ & $\mathrm{Al}_{2} \mathrm{O}_{3}$ & $\mathrm{Fe}_{2} \mathrm{O}_{3}$ & $\begin{array}{c}\mathrm{MnO}+ \\
\mathrm{MgO}+ \\
\mathrm{CaO}+ \\
\mathrm{Na}_{2} \mathrm{O}+ \\
\mathrm{K}_{2} \mathrm{O} \\
\end{array}$ & $\mathrm{P}_{2} \mathrm{O}_{5}$ & LOI & Total & $\begin{array}{c}\mathrm{Al}_{2} \mathrm{O}_{3} \\
\text { em base } \\
\text { calcinada }\end{array}$ & $\begin{array}{c}\mathrm{Al}_{2} \mathrm{O}_{3} / \\
\mathrm{SiO}_{2}\end{array}$ & $\begin{array}{c}\mathrm{Cl}_{2} \mathrm{O}_{3} \\
+ \\
\left.\mathrm{Fe}_{2} \mathrm{O}_{3}\right) \\
/ \mathrm{SiO}_{2}\end{array}$ & $\begin{array}{c}\left(\mathrm{K}_{2} \mathrm{O}+\right. \\
\left.\mathrm{Na}_{2} \mathrm{O}\right) \\
\mathrm{Al}_{2} \mathrm{O}_{3}\end{array}$ & $\begin{array}{c}\left(\mathrm{K}_{2} \mathrm{O}+\right. \\
\mathrm{Na}_{2} \mathrm{O}+ \\
\mathrm{CaO}+ \\
\mathrm{MgO}) / \\
\mathrm{Al}_{2} \mathrm{O}_{3} \\
\end{array}$ \\
\hline $\begin{array}{c}\text { Argila } \\
\text { Aluminosa }\end{array}$ & 21,6 & 4,1 & 49 & 0,75 & 0,01 & 0,05 & 24 & 100 & 64,6 & 0,04 & 0,05 & 0,12 & 0,14 \\
\hline Plintita & 23,7 & 3,5 & 47,6 & 2,66 & 0,01 & 0,05 & 22 & 100 & 61,2 & 0,16 & 0,18 & 0,01 & 0,01 \\
\hline Alterita & 80,4 & 0,3 & 12,7 & 1,45 & 0,01 & 0,03 & 4,9 & 100 & 13,3 & 2,01 & 2,12 & 0 & 0 \\
\hline Arenito & 92,5 & 0,4 & 3,5 & 1,22 & 0,05 & 0,03 & 1,6 & 100 & 3,6 & 2,27 & 2,3 & 0 & 0 \\
\hline
\end{tabular}

Do arenito para a argila aluminosa ocorre acentuada perda de $\mathrm{SiO}_{2}$ (de 92,5 para $21,64 \%$ ), acompanhado de enriquecimento em $\mathrm{Al}_{2} \mathrm{O}_{3}$ (de 3,59 a 49,05\%). Os valores de silício e de alumínio são similares entre a plintita e a argila aluminosa e ambos diferem da alterita e do arenito.

0 conjunto dos dados indica enriquecimento progressivo de alumínio da base para o topo do perfil $(3,59,12,7,47,69$ e 49,05\%). Em relação ao $\mathrm{Fe}_{2} \mathrm{O}_{3}$, quando se compara com a rocha sã $(1,22 \%)$, há enriquecimento contínuo na alterita $(1,45 \%)$ e na plintita, sendo que este horizonte se caracteriza pelo maior teor de $\mathrm{Fe}_{2} \mathrm{O}_{3}(2,66 \%)$ enquanto a argila aluminosa se caracteriza pelo menor teor $(0,75 \%)$.

A maior proporção de hematita ocorre no arenito e na plintita. (Tab. 2 A). A presença da hematita como óxido predominante foi determinada utilizando o índice de avermelhamento da matriz do solo (RR) proposto por Torrent \& Barrón (1993). Nos solos tropicais há relação positiva entre sua cor vermelha e a presença da hematita. Este mineral determina o avermelhamento do solo em condições de boa drenagem ou quando cimentados em crostas e nódulos (Torrent \& Barrón, 1993; Nahon, 1986). A presença da goethita na alterita é reconhecida pela cor amarela do plasma (ver os difratogramas de raios $\mathrm{X}$ ).

Tabela 2. Presença de hematita nos horizontes analisados (Argila Aluminosa, Alterita, Plintita e Arenito) baseado no índice RR (Redness Rate) proposto por Torrent \& Barrón (1993).

\begin{tabular}{lcc}
\hline \multicolumn{1}{c}{ Amostra } & Cor Munsell & RR \\
\hline Argila aluminosa & $5 Y$ 8/1 & 0 \\
Plintita & $10 \mathrm{R} \mathrm{6/4}$ & 6,7 \\
Alterita & $10 \mathrm{YR} 8 / 3$ & 0 \\
Arenito & $10 \mathrm{R} 7 / 3$ & 4,3 \\
\hline
\end{tabular}

A mobilidade geoquímica dos elementos $\mathrm{Si}$, Fe e Al em relação ao arenito é apresentada na figura 5 . Na alterita, há ganhos absolutos de $\mathrm{Si}, \mathrm{Al}$ e Fe. A relação entre Ti e Si indica perdas deste elemento na plintita e, em igual proporção, na argila aluminosa. Em relação ao Fe, há perda progressiva relativa ao enriquecimento do Ti na plintita e na argila aluminosa e, finalmente, em relação ao $\mathrm{Al}$, observa-se ganhos positivos na alterita, plintita e na argila aluminosa.

Os resultados de ATD-TG da fração argila indicam que a paragênese secundária caulinita e gibbsita predomina em todos os horizontes (Tab. 3). 

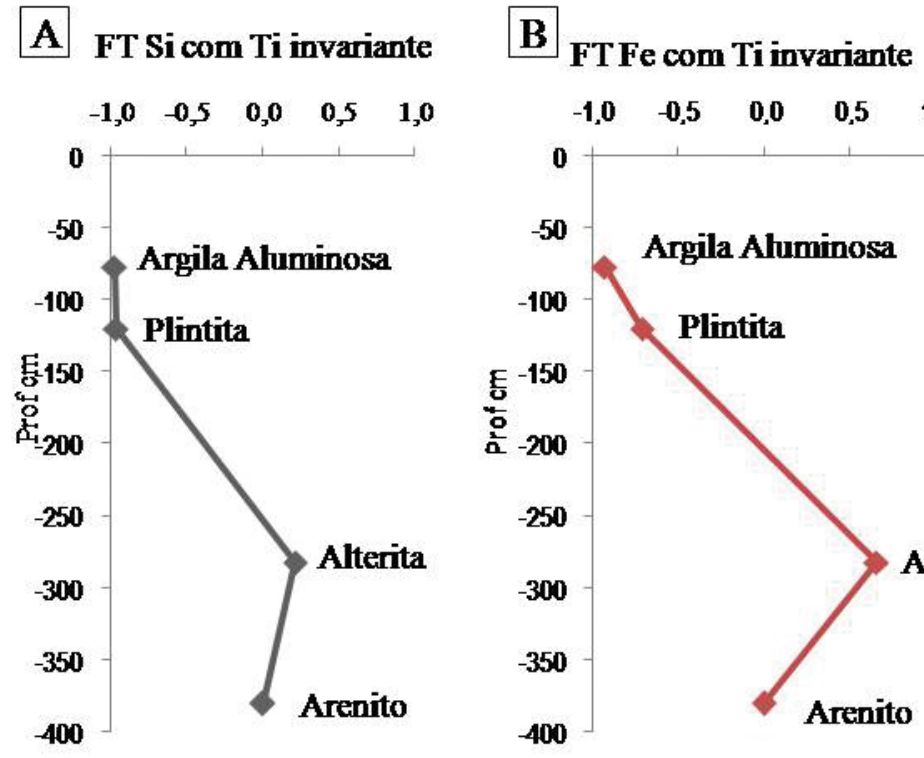

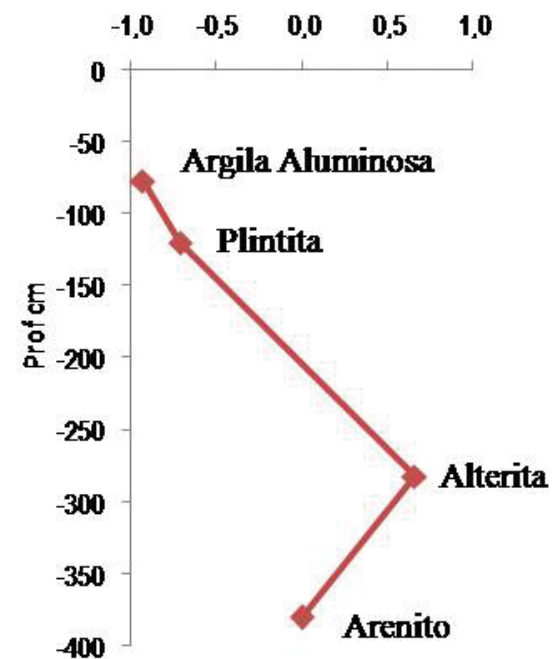

\section{FT Al com Ti invariante}

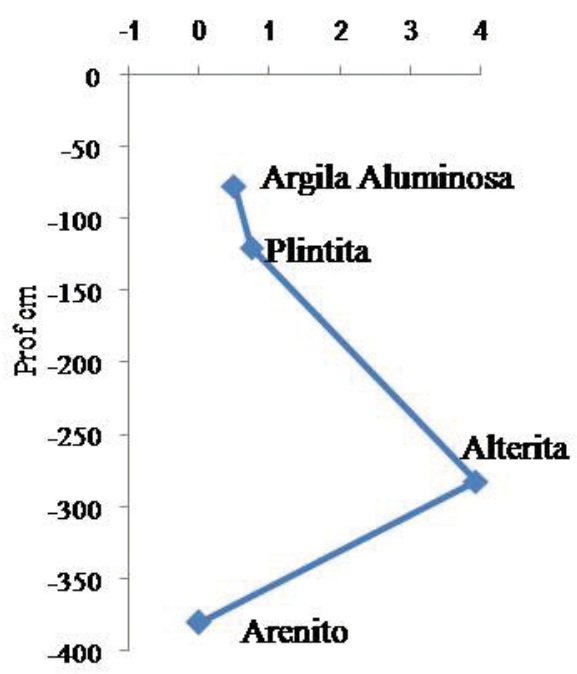

Figura 5. Função de Transporte Geoquímico (Chadwick, 1990) mostrando as variações negativas do Si e do Fe nos horizontes de plintita e argila aluminosa e as variações positivas do Al na alterita, plintita e argila aluminosa ligadas ao aumento da gibbsita no perfil. A) Silício com Titânio invariante; B) Ferro com Titânio invariante; C) Alumínio com Titânio invariante.

Tabela 3. Semiquantificação por ATD/TG da caulinita e gibbsita na fração argila indicando diminuição da caulinita e aumento da gibbsita da base (arenito) para o topo (argila aluminosa) do perfil. Apresentando ainda a posição das amostras de Arenito, Alterita, Plintita e Argila Aluminosa.

\begin{tabular}{cccccc}
\hline Amostra & \multicolumn{2}{c}{ Gibbsita } & \multicolumn{2}{c}{ Caulinita } & Mulita \\
\hline & $\%$ & $\mathrm{~T}\left({ }^{\circ} \mathrm{C}\right)$ & $\%$ & $\mathrm{~T}\left({ }^{\circ} \mathrm{C}\right)$ & $\mathrm{T}\left({ }^{\circ} \mathrm{C}\right)$ \\
Argila & 71,43 & 300,33 & 28,29 & 499,34 & 988,28 \\
aluminosa & & & & & \\
Plintita & 62,24 & 299,81 & 34,81 & 497,59 & 993,27 \\
Alterita & 4,42 & 263,83 & 88,57 & 528,46 & 976,42 \\
Arenito & 3,75 & 267,46 & 72,28 & 531,81 & 980,42 \\
\hline
\end{tabular}

No arenito a caulinita corresponde a $72,28 \%$ enquanto a gibbsita corresponde a 3,75\%. Na argila aluminosa a caulinita corresponde a apenas $28,29 \%$ e a gibbsita $71,43 \%$. Concentração expressiva de gibbsita também foi encontrada na plintita $(62,24 \%)$. Os resultados indicam que a alteração do arenito e a pedogênese implicam no aumento expressivo da gibbsita formada pela destruição da caulinita, processo coerente com o meio ácido e intensamente lixiviado. 0 arenito se revela como uma rocha de natureza não exclusivamente quartzosa, mas feldspática (observado em microscopia optica), micácea e caulinítica associada com oxihidróxidos de ferro e alumínio, cujos produtos de alteração são majoritariamente argilominerais secundários cauliníticos e presença de gibbsita. Os minerais hidratados de alumínio se formam e estabilizam nos níveis superiores dos perfis de alteração após intensa dessilicificação ou nos níveis lateríticos endurecidos ou nodulares (Trolard \& Tardy, 1987; Melfi, 1997). A desferruginização enriquece a matriz da argila aluminosa em caulinita e gibbsita.

\section{Discussão dos resultados}

Em um perfil laterítico, a alterita é um horizonte de perda geoquímica exceto em relação à redistribuição do ferro e alumínio e pela pedoplasmação caulinítica (Tardy, 1993). A plintita é um horizonte pedológico que evolui em detrimento da alterita e é composto por caulinita secundária e por domínios que representam perdas e acúmulo de ferro (hematita e goethita) (Tardy, 1993). A plintita se desenvolve na base de horizontes bem drenados situados nas posições elevadas do relevo ou em posições topograficamente deprimidas e submetidas a ciclos de redução, transferência e 
oxidação dos compostos ferruginosos pela oscilação do nível freático (Vepraskas, 1992).

Do ponto de vista morfológico e petrográfico o horizonte plíntico perde completamente a estrutura da rocha e a redistribuição do ferro gera manchas de cores cinza e amarela representando as perdas geoquímicas e que se associam com volumes nodulares vermelhos escuros indicando núcleos de concentração absoluta. As manchas possuem significado genético e mineralógico. Os nódulos são concentrações hematíticas formadas por precipitação do ferro nas microporosidades, as manchas amarelas são cauliníticas e goethíticas orientadas pela porosidade e os volumes cinza desferruginizados são formados por caulinita e quartzo, caracterizando domínios de eluviação (Nahon, 1986).

A evolução da alterita em plintita ocorre pela liberação do ferro de acordo com o desenvolvimento do solo. Por outro lado, na plintita, a mudança de cor do vermelho para o amarelo indica dissolução da hematita e formação da goethita em ambientes mais hidratados e redutores. A intensidade e o grau de intemperismo refletem na mineralogia e química do regolito enquanto a lixiviação determina a remobilização, perda e o enriquecimento de elementos químicos que podem ser afetados por mudanças do nível freático e do fluxo de água dentro do solo (Guan et al., 2001).

A relação sílica/alumínio decresce sistematicamente do arenito para o horizonte de argila aluminosa (de 2,27 para 0,04) representando o aumento da fase argilosa (Tab. 1). 0 índice que relaciona os metais alcalinos e as bases totais com o alumínio reflete a natureza ácida do arenito e alterita e um ligeiro aumento relativo do $\mathrm{Al}_{2} \mathrm{O}_{3}$ compondo a fase residual ligada ao intemperismo químico na plintita e argila aluminosa.

Em um perfil laterítico típico (bem drenado), existe uma correlação positiva no comportamento geoquímico do $\mathrm{Al}$, $\mathrm{Fe}$ e $\mathrm{Ti}$, sendo considerados residuais e imóveis (Burak et al., 2010). 0 Fe e o $\mathrm{Al}$ apresentam comportamento similar ao formar minerais secundários como hematita, goethita e gibbsita. 0 comportamento dos elementos no perfil estudado é um indicativo do ambiente de formação no qual, em pH ácido, a Si se torna móvel e é lixiviada do perfil. 0 mesmo ocorre com o Fe, que é solubilizado e lixiviado do perfil, processo determinado pela hidromorfia. De forma geral, a evolução geoquímica do perfil tende à aluminização.

Com base nos dados obtidos e por ocupar apenas as depressões topográficas, a gênese do horizonte de argila aluminosa relaciona-se a desferruginização do horizonte plíntico, mantendo a textura argilosa e aumentando a constituição aluminosa. Em ambiente saturado como o da área de estudo, o ferro dissolvido $\left(\mathrm{Fe}^{2+}\right)$ é altamente susceptível de ser exportado com a solução do solo (Fritsch et al., 2002), resultando em um horizonte caulinítico com baixo ferro e elevado teor em $\mathrm{Al}_{2} \mathrm{O}_{3}$. Este horizonte é quimicamente similar à plintita, exceto pelo menor teor de ferro. A composição química e mineralógica obtida não reflete descontinuidade marcante entre a rocha e os horizontes de alteração e pedogênese, indicando estreita similaridade.

A alteração mineralógica primária forma um sistema de porosidade fina que é preenchido por argila (microssistemas plásmicos), progressivamente ampliado concomitante ao avanço do intemperismo e a pedogênese. No arenito, além da presença de fissuras preenchidas por oxidróxidos de ferro, foram encontrados cristais de feldspato potássico muito alterados. Em meio tropical úmido, a via de alteração normal por dissolução dos grãos de feldspato é a neoformação caulinítica e, em casos extremos, a formação de gibbsita (Melfi et al., 1999).

$\mathrm{Na}$ alterita ampliam-se as zonas cauliníticas desenvolvidas in situ (processo de alteroplasmação), sem qualquer orientação, próprias de material neoformado associado, localmente, com zonas que possuem argilominerais micáceos (illita orientada paralelamente) (não identificados por raios $\mathrm{X}$ devido à baixa concentração) além do quartzo. Comparado ao arenito, apresenta zonas amarelas claras devido à remobilização do ferro no horizonte.

Na alterita, os nódulos hematíticos localizados próximo ao plasma de coloração avermelhada (plasma ferruginoso), se prolongam e se concentram mais fortemente na plintita, que corresponde às fácies ferruginosas mais endurecidas formadas por caulinita e hematita com córtex de alteração amarelo e zonas desferruginizadas cinza claras refletindo a flutuação do nível freático.

As acumulações ferruginosas endurecidas argilomorfas podem se formar a partir de embasamento arenoso desde que a evolução geoquímica condicione a alteração do mineral (Nahon, 1976).

A dissolução a partir de soluções ácidas (dissolução incongruente responsável pela lixiviação de cátions básicos e sílica do regolito) e os ambientes com elevada temperatura e umidade aceleram a dissolução do quartzo e a formação precoce dos minerais aluminosos secundários (caulinita e gibbsita), condições que favorecem a argilização e desenvolvimento da litomargem caulinítica e a bauxitização (Tardy, 1993). Estes processos expli- 
cam a formação de horizontes argilosos e aluminosos a partir da alterita rica em quartzo.

Os nódulos hematíticos podem se dissolver quando os parâmetros hidrostáticos que regem as relações ferro-argila são modificados (Tardy, 1993). A dissociação entre o ferro e a argila corresponde aos domínios amarelos distribuídos próximos aos vazios ou impregnando suavemente a matriz cinza clara argilosa caulinítica. Em meio aeróbico, o intemperismo produz óxidos de ferro de baixa mobilidade e solubilidade, especialmente hematita e goethita. Ao contrário, em ambiente redutor, a remobilização do $\mathrm{Fe}^{2+}$ resulta na distribuição heterogênea dos óxidos de ferro e na formação de horizontes manchados (plintita) (Schwertmann, 1985).

A drenagem interna do perfil e a diluição das soluções nos horizontes superiores do perfil são intensificadas pela pedogênese. A bioturbação e a presença da gibbsita na matriz argilosa da plintita e a argila aluminosa formam uma estrutura granular fina com o desenvolvimento de uma rede de porosidade que permite o fluxo rápido da água, acentuando as transferências químicas.

A superfície plana da chapada constitui-se em outro importante fator, direcionando verticalmente o fluxo das soluções. As superfícies geologicamente antigas e tectonicamente estáveis das regiões tropicais quentes e úmidas, sustentadas por rochas do embasamento pré-cambriano ou de origem sedimentar, após intensivo intemperismo iniciado provavelmente no início do Mesozóico, apresentam regolitos de composição geoquímica e mineralógica relativamente monótonos formados por caulinita, óxidos e hidróxidos de $\mathrm{Fe}$ e $\mathrm{Al}$ e quartzo residual (Melfi, 1997). A composição mineralógica e geoquímica dos horizontes estudados são coerentes com os processos de evolução apresentados.

Finalmente, a desferruginização resulta no horizonte aluminoso, extraído como argila refratária, uma vez que a depressão topográfica está ligada ao eixo de drenagem. 0 fluxo lateral da solução do solo é um mecanismo eficiente de lixiviação geoquímica e de formação de um horizonte branco desferruginizado (Peterschimitt et al., 1996; Rosolen et al., 2002) e se caracteriza como um ataque que transforma as paisagens antigas destruídas por desequilíbrios biogeoquímicos (Boulet, 1974).

\section{Conclusões}

No perfil estudado, a neoformação caulinítica associada com gibbsita constitui-se na paragênese mineral secundária principal do perfil.
A matriz secundária predominantemente gibbsítica com caulinítica se forma no topo da alterita, com a individualização do horizonte plíntico, onde há também a acumulação absoluta de hematita na forma de nódulos. A caulinita se forma por alteração do feldspato e dos minerais micáceos (muscovita/illita), além de estar relacionada com a própria natureza do arenito. A gibbsita é o hidróxido fundamental nos horizontes pedogenéticos e sua gênese pode estar relacionada com a excessiva dessilicificação do meio em condições ácidas.

Os grãos de quartzo abundantes no arenito e alterita diminuem consideravelmente na plintita e na argila aluminosa. Atualmente este nível argilo-aluminoso é reconhecido no campo por sua cor branca, sobrepondo-se à plintita e nas depressões topográficas hidromórficas. A desferruginização da plintita é a origem deste material, empobrecido igualmente em ferro e sílica. 0 balanço geoquímico mostra que o alumínio é o único elemento de enriquecimento nos horizontes quando comparado ao arenito.

As características petrográficas, químicas e mineralógicas dos regolitos tropicais são profundamente complexas por se desenvolverem ao longo de vários ciclos de mudanças paleoambientais e paleoclimáticas, exigindo o refinamento da pesquisa para aprofundar a compreensão da evolução da paisagem na história geológica do Triângulo Mineiro.

Agradecimentos - À FAPESP pela concessão de bolsa da primeira autora (Proc. $n^{\circ}$ 2013/15942-1) e pelo financiamento do projeto de pesquisa (Proc. $\mathrm{n}^{\circ}$ 2014/01131-4). Os resultados apresentados fazem parte da dissertação de mestrado da primeira autora.

\section{Referências}

Batezelli, A., Saad, A.R., Perinotto, J.A.J.; Fulfaro, V.J. \& Etchebehere, M.L.D.C. 2003. Análise estratigráfica aplicada à Formação Araçatuba (Grupo Bauru-Ks) no centro-oeste do Estado de São Paulo. Geociências, 22(1): 5-32.

Borges, F.A. 2012. Caracterização temporal das áreas úmidas e de preservação permanente da porção de alto e médio curso da bacia hidrográfica do rio Uberabinha (MG) com a aplicação de técnicas de geoprocessamento. Uberlândia, $135 \mathrm{p}$. Dissertação de Mestrado, Programa de Pós-Graduação em Geografia, Instituto de Geografia, Universidade Federal de Uberlândia.

Boulet, R. 1974. Toposéquences et sols tropicaux en Haute Volte: équilibres dynamiques et bioclimats. Strasbourg, 330p. Tese de Doutorado, Programa de Ciências Naturais, Universidade de Strasbourg.

Brimhall, G.H., Lewis, C.J., Ford, C., Bratt, J., Taylor, G. \& 
Warin, O. 1991. Quantitative geochemical approach to pedogenesis: importance of parent material reduction, volumetric expansion, and eolian influx in lateritization. Geoderma, 51: 51-91.

Burak, D.L., Fontes, M.P.F., Santos, N.T., Monteiro, L.V.S., Martins, E.S. \& Becquer, T. 2010. Geochemistry and spatial distribution of heavy metals in Oxisols in a mineralized region of the Brazilian Central Plateau. Geoderma, 160(2): 131-142.

Butt, C.R.M., Lintern, M.J. \& Anand, R.R. 2000. Evolution of regoliths and landscapes in deeply weathered terrain - implications for geochemical exploration. Ore Geology Reviews, 16: 167-183.

Chadwick, O.A., Brimhall, G.H. \& Hendricks, D.M. 1990. From a black to a gray box-a mass balance interpretation of pedogenesis. Geomorphology, 3 (3): 369-390.

Chen, M., Liu, C., Li, F., Zhai, G., Liu, H., Liu, C. \& Yu, W. 2014. Correlations between soil geochemical properties and $\mathrm{Fe}^{(\mathrm{III})}$ reduction suggest microbial reducibility of iron in different soils from Southern China. Catena, 123: 176-187.

Corrêa, G.F. 1989. Les microreliefs "murundus" et leur environment pédologique dans l'ouest du Minas Gerais, région du Plateau Central brésilien. Vandoeuvre-les-Nancy Nancy, 144p. Tese de Doutorado, École Pétrographiques et Géochimiques, Université de Nancy I.

Corrêa, W.L.P. 2006. Contribuição à gênese e caracterização tecnológica das argilas da região de Uberaba, Minas Gerais. São Paulo, 143p. Tese de Doutorado, Programa de Pós-Graduação em Geoquímica e Geotectônica, Instituto de Geociências, Universidade de São Paulo.

Costa, M.L., Sousa, D.J.L. \& Angélica, R.S. 2009. The contribution of lateritization processes to the formation of the kaolin deposits from eastern Amazon. Journal of South American Earth Sciences, 27: 219-234.

Fabris, J.D., Viana, J.H.M., Schaefer, C.E.G.R., Wypych, F. \& Stucki, J.W. 2009. Métodos físicos de análises em mineralogia do solo. In: Melo, V.F., Alleoni, L.R.F. (Eds.), Química e Mineralogia dos Solos, Parte I. Viçosa, SBCS, p. 612-695.

Fernandes, L.A. 2004. Mapa litoestratigráfico da parte oriental da Bacia Bauru (PR, SP, MG), escala 1:1.000.000. Boletim Paranaense de Geociências, 55.

Fernandes, L.A. \& Coimbra, A.M. 1996. A Bacia Bauru (Cretáceo Superior, Brasil). Anais da Academia Brasileira de Ciências, 68(2): 195-205.

Fernandes, L.A. \& Coimbra, A.M. 2000. Revisão estratigráfica da parte oriental da Bacia Bauru (Neocretáceo). Revista Brasileira de Geociências, 30(4): 717 728.

Fritsch, E., Montes-Lauar, C.R., Boulet, R., Melfi, A.J., Balan, E. \& Magat, Ph. 2002. Lateritic and redoximorphic features in a faulted landscape near Manaus, Brazil. European Journal of Soil Science, 53: 203-218.

Fritsch, E., Morin, G., Bedidi, A., Bonnin, D., Balan, E., Caquineau, S. \& Calas G. 2005. Transformation of hematite and $\mathrm{Al}$-poor goethite to $\mathrm{Al}$-rich goethite and associated yellowing in a ferralitic clay soil profile of middle Amazon basin (Manaus, Brazil). European Journal of Soil Science, 56: 575-588.

Guan, P., Ng, C., Sun, M. \& Tang, W. 2001.Weathering indices for rhyolitic tuff and granite in Hong Kong. Engineering Geology, 59: 147-159.

Ishida, D.A. 2010. Caracterização e gênese de solos e de depósito de caulim associado, São Gabriel da Cachoeira - AM. São Paulo, 192 p. Tese de Doutorado, Programa de Geoquímica e Geotectônica, Instituto de Geociências, Universidade de São Paulo.

Lara, M.P. 1997. As argilas do platô de Uberaba (MG): micromorfologia, mineralogia e geoquímica. Implicações genéticas. Ouro Preto, 91p. Dissertação de Mestrado, Programa de Pós-graduação em Evolução Crustal e Recursos Naturais, Universidade Federal de Ouro Preto.

Melfi, A.J. 1997. Brazilian bauxite deposits: a review. In: Carvalho, A., Boulangé, B., Melfi, A.J. \& Lucas, Y (Eds.). Brazilian bauxites. São Paulo-Paris, USP-FAPESP-ORSTOM, p. 03-22.

Melfi, A.J., Cerri, C.C., Fritsch, E. \& Formoso, M.L.L. 1999. Tropical soils: genesis, distribution and degradation of lateritic pedological systems. In : Formoso, M.L.L. \& Cerri, C.C. (Org.). Workshop on Tropical Soils. Rio de Janeiro, Academia Brasileira de Ciências,p. 7-30.

Melfi, A.J., Trescases, J.J. \& Oliveira, S.M.B. 1979. Les "latérites" nickélifères du Brésil. Cahier ORSTOM, série Géology, XI(1): 15-42.

Montes, C.R., Melfi, A.J., Carvalho, A., Vieira-Coelho, A.C. \& Formoso, M.L.L. 2002. Genesis, mineralogy and geochemistry of kaolin deposits of the Jari River, Amapá State, Brazil. Clays and Clay Minerals, 50(4): 494-503.

Nahon, D.B. 1976. Cuirasses ferrugineuses et encroûtments calcaires au Sénégal Occidental et en Mauritanie. Systèmes évolutifs: géochimie, structures, relais et coexistence. Marseille, 232p. Tese em Ciências Naturais, Université de Droit, d'Economie et des Sciences d'Aix-Marseille.

Nahon, D. 1986. Evolution of iron crusts in tropical landscapes. In: Coleman, S.M. \& Dethier, D.P. (Eds.). Rates of chemical weathering of rocks and minerals. New York, Academic Press Inc, p. 169-191.

Nahon, D. B., Melfi, A.J. \& Conte, C.N. 1989. Présence d'un vieux système de cuirasses ferrugineuses latéritiques en Amazonie du Sud. Sa transformation in situ en latosols sous la forêt équatoriale actuelle. Comptes Rendus de l'Académie de Sciences, 308 (II): 755-760.

Peterschimitt, E., Fritsch, E., Rajot, J.L. \& Herbillon, A.J. 1996. Yellowing, bleaching and ferritisation processes in soil mantle of the Western Ghâts, South India. Geoderma, 74: 235-253.

Queiroz, A.T. 2012. Análise e avaliação da demanda e da disponibilidade hídrica nos alto e médio curso do Rio Uberabinha e o abastecimento público em Uberlândia (MG). Uberlândia, 137 p. Dissertação de Mestrado, Programa de Pós-Graduação em Geografia, Instituto de Geografia, Universidade Federal de Uberlândia.

Riccomini, C. 1997. Arcabouço estrutural e aspectos do tectonismo gerador e deformador da Bacia Bauru no 
Estado de São Paulo. Revista Brasileira de Geociências, 27(2): 153-162.

Ribeiro, D.T.P. 2001. Diagênese das rochas do Membro Serra Da Galga, Formação Marília, Grupo Bauru (Cretáceo Da Bacia Do Paraná), na região de Uberaba, Minas Gerais. Revista Brasileira de Geociências, 31(1): 7-12.

Rosolen, V., Lamotte, M., Boulet, R., Trichet, J., Rouer, O. \& Melfi, A.J. 2002. Genesis of a mottled horizon by Fe-depletion within a laterite cover in the Amazon Basin. Comptes Rendus de l'Académie de Sciences, Série Geoscience, 334 : 187-195.

Rosolen, V., Oliveira, D.A. \& Bueno, G.T. 2014. Vereda and murundu wetlands and changes in brazilian environmental laws: challenges to conservation.Wetlands Ecology and Management v. 23, n. 2, p. 285292.

Sampaio, J.A., Andrade, M.C. \& Dutra, A.J.B. 2005. Bauxita. In: Luz, A.B \& Lins, F.F. (Ed.). Rochas \& Minerais Industriais: Usos e Especificações. Rio de Janeiro, CETEM, p. 279- 304.

Schwertmann, U. 1985. The effect of pedogenic environments on iron oxide minerals. Advances in Soil Science, $1: 171-200$

Suguio, K. 1973. Formação Bauru. Calcários e sedimentos detríticos associados. São Paulo, 236p. Tese de Livre Docência, Instituto de Geociências, Universidade

Man. 560 .

Editores: Rômmulo V. Conceição \& Paulo A. Souza. de São Paulo.

Suguio, K., Barcellos, J.S. \& Moniz, A.C. 1976. Caracterização sedimentológica e mineralógica de formações superficiais argilo-arenosas peculiares dos planaltos do Triângulo Mineiro e Alto Paranaiba. In: CONGRESSO BRASILEIRO DE GEOLOGIA, 29, 1976, Ouro Preto. Anais..., Ouro Preto, SBG, vol. 1, p. 241-247.

Tardy, Y. 1993. Pètrologie des laterites et des sols tropicaux. Masson, Paris, p. 459.

Tavares, C.P., Candeiro, C.R.A. \& Simbras, F. 2012. Levantamento da geologia da Bacia Bauru (Cretáceo Superior) na região pontal do Triângulo Mineiro, Minas Gerais. Horizonte, 6(1).

Torrent, J. \& Barrón, V. 1993. Laboratory measurement of soil color: theory and practice. In: Bigham, J.M. \& Ciolkosz, E.J. (Eds.), Soil color. Madison, Soil Science Society of America. p. 21-33.

Trolard, F. \& Tardy,Y. 1987. The stabilities of gibbsite, boehmite, aluminous goethites and aluminous hematites in bauxites, ferricretes and laterites as a function of water activity, temperature and particle size. Geochimica et Cosmochimica Acta, 51: 945-957. Vepraskas, M.J. 1992. Redoximorphic features for identifying aquic conditions. Technical Bulletin, North Carolina, North Carolina State University, USA, p. 301. 
